\title{
Extracts of Red Yolk from Duck Eggs Inhibit Metastasis of Human Mammary Carcinoma (4T1) Cells in Mice
}

\author{
Song Qi-bin ${ }^{1}$, Yao Yi ${ }^{*}$, Hu Wei-guo ${ }^{1}$, Zhang Sheng-hua ${ }^{2}$, Yan Xiao-wei ${ }^{1}$ and Yang Rui ${ }^{1}$ \\ ${ }^{I}$ Oncology Center; Renmin Hospital of Wuhan University; Wuhan 430060; P R-China. ${ }^{2}$ College of Food Science \\ and Technology; Huazhong Agricultural University; Wuhan 430070, P R - China
}

\begin{abstract}
The aim of the present study was to investigate the in vivo anti-metastatic activity of the red pigments of red yolk eggs laid by the ducks dieting on Potamogeton cripus $L$ on the mammary carcinoma (4T1). The pigments were extracted with petroleum ether and acetone $(2: 1, v / v)$. BALB/c mice were divided into three groups $(n=6)$, fed with the extracts at $150 \mathrm{mg} / \mathrm{kg}$ body weight (BW)/day (DEYE-H) or at $50 \mathrm{mg} / \mathrm{kg}$ BW/day (DEYE-L) and identical buffer without the extract (control group). The extracts were administered for 34 days. The treatment significantly inhibited the growth of orthotopical $4 T 1$ tumour (DEYE-H vs control, 1:2; DEYE-L vs control, 2:3) and reduced the metastasis of tumour in the lungs (DEYE-H vs control, 4:7; DEYE-L vs control, 5:7), without statistical difference of body weight among the three groups.
\end{abstract}

Key words: duck egg yolk, extracts, mammary carcinoma, metastasis, 4T1 Cells, BALB/c mice

\section{INTRODUCTION}

The compounds of the carotenoid family of tetraterpenoids occur widely in nature and have been extensively studied. Among these, the best known is probably $\beta$-carotene, a precursor of vitamin $\mathrm{A}$. Besides having therapeutic uses for the treatment of eye diseases, carotenoids also show promising effects on certain cardiovascular diseases, carcinomas, photoallergies, immune deficiency and aging processes. Carotenoids are widely employed in clinical medicine and in the pharmaceutical, food and cosmetics industries. Several compounds in this family show biological activities which include anti-oxidation, immune system regulation and inhibition of tumour growth (Granados-Principal et al., 2010; Tapiero et al., 2004).
Carotenoids are not synthesized by the human body and are provided through the consumption of various dietary elements, including carrots, beetroots, sweet potatoes, tomatoes, Chaenomelis fructus (Chinese quince), Mangifera indica (mango) and green vegetables. Egg yolks are also an important dietary source of carotenoids and it has been shown that the colour of the yolk is closely related to the type and concentration of carotenoids present, which may include lutein, zeaxanthin, neoxanthin and violaxant (Hammershoj et al., 2010).

Eggs with red yolks are laid by the ducks living in some areas of freshwater lakes in China. The areas are characterized by the occurrence of Potamogeton crispus $L$, a submersed herbaceous perennial plant growing in freshwater lakes,

*Author for correspondence: yivanrobin@yahoo.com.cn 
ponds, paddy fields and rivers. The species is an important primary producer in these freshwater ecosystems, providing a good food source for herbivorous fishes and birds (Jian et al., 2003). The egg yolks of ducks feeding on the plant vary from salmon pink to cardinal red and their yolk colour score can reach 15 on the Roche Yolk Colour (RYC) fan (Hasin et al., 2006). The eggs are appreciated for their delicious taste by the Chinese consumers and also by people from Europe and North America.

In our previous studies, we identified major carotenoids from the red yolks as rhodoxanthin and its isomers (Liu et al., 2006; Wang et al., 2003). In vitro studies have indicated that the duck egg yolk extracts (DEYE) could inhibit the growth of hepatoma carcinoma (QGY-7703) cells and accelerate their apoptosis (Liu et al., 2004b). In vivo studies have also suggested that DEYE could hinder the growth of sarcoma (S180) in mice (Liu et al., 2003). The present study aimed to determine the capacity of DEYE to inhibit the growth of orthotopic 4T1 tumour in mice and the spread of metastatic tumours in the lungs.

\section{MATERIALS AND METHODS}

Fresh duck eggs were supplied by Hubei Jiuzhu Egg Industry Co., Ltd, China. Only the eggs possessing a RYCF $>15$ were used. The cancer cell line 4T1 was obtained from the China Center for Typical Culture Collection (CCTCC) (Wuhan University, Wuhan, China). 4T1 is an oestrogenindependent mammary carcinoma, derived from mammary epithelial carcinoma from BALB/c the mice (BALB/cfC3H). 4T1-derived tumours mimic the clinical breast cancer and are highly metastatic (Dey et al., 2010). The cells were grown in Dulbecco's Modified Eagle Medium supplemented with $10 \%$ faetal bovine serum and antibiotics (complete medium). Monoclonal mouse anti- proliferating cellular nuclear antigen (PCNA) antibody was obtained from Biogenex, Inc., San Ramon, CA. Enhanced chemiluminescence (ECL) detection kit was from R\&D Biotechnology, USA. The secondary antibody was goat anti-mouse horseradish peroxidase (Promega, Madison, Wisconsin, USA). Propidium iodide and DNasefree RNase A were from Sigma-Aldrich, Missouri, USA. Ultrasonic Cell Disruptor (JY98-IIIN) was from Beijing JinMei Shengshi Laboratory Equipment Co., Ltd, China.
All of the following procedures were carried out away from sunlight. The duck egg yolks were lyophilized for $36 \mathrm{~h}$ and ground into powder. The pigment in the yolk powder was extracted with a mixture of petroleum ether and acetone $(2: 1, \mathrm{v} / \mathrm{v})$ at room temperature until the powder became colourless. The mixture was then placed into a separating funnel together with an equal volume of physiological saline. When the phases were separate, the upper phase was collected and defatted on a chromatographic column (diameter $60 \mathrm{~mm}$, height $10 \mathrm{~cm}$ ) of G90 silica gel. Petroleum ether was used as mobile phase. The eluted red pigment fraction, termed DEYE, was concentrated under vacuum. The DEYE was then conserved at $4^{\circ} \mathrm{C}$ until use.

For animal experiments, the DEYE was added to phosphate buffered saline (PBS) (including 2\% Tween 20) to final concentrations of either $15.0 \mathrm{mg} / \mathrm{ml}$ or $5.0 \mathrm{mg} / \mathrm{ml}$. The solutions were emulsified with ultrasound before oral administration to the animals by a syringe. The experiments were conducted according to the guidelines of animal study in China, and the study protocol was approved by the Wuhan University Committee on Ethics of Animal Experiments. Eighteen 4-week-old female BALB/c mice (weighing 16.9 $\pm 0.8 \mathrm{~g}$ ) were purchased from the Experimental Animal Center, Institute of Health and Epidemic Prevention, Wuhan, China. They were kept in a controlled environment with a 12-h photoperiod and had free access to food and water. The mice were randomly divided into three groups $(n=6)$, termed DEYE-H, DEYE-L and control. After a week of adaptive feeding, the mice were orally administrated DEYE emulsion or placebo (the control group) daily for 34 days. Mice in the DEYE-H group were given high-dose DEYE [150 $\mathrm{mg} / \mathrm{kg}$ body weight (BW) per day], mice in the DEYE-L group were given low-dose DEYE (50 $\mathrm{mg} / \mathrm{kg} \mathrm{BW}$ per day) and those in the control group were administered an equal volume of an identical emulsion without DEYE. After four days of administration, 4T1 cells were transplanted orthotopically into the mammary fat pads $\left(1.7 \times 10^{5}\right.$ cells /pad /mouse in $100 \mu \mathrm{l}$ ) of all the animals.

For all the mice, BW was measured each day and mammary tumour size every three days. Tumour size was measured by callipers in two dimensions and volumes were calculated using the formula (width ${ }^{2} \times$ length)/2. At the end of the experiment (30 days after injection of tumour cells), the mice were asphyxiated by $\mathrm{CO}_{2}$ and the breast tumours 
and organs (brain, lung, liver, spleen) were collected.

The photographs of the macroscopic structure of all five lung lobes of each mouse were taken at the time of killing. Lungs were examined visually and the numbers of pulmonary tumours were determined by counting the tumour foci (Huang et al., 2008). Quantitative analysis of lung metastasis and the cross-sectional area of tumours in randomly selected fields were measured using the Image Pro Plus software (Media Cybernetics).

Approximately $100 \mathrm{mg}$ of lung tissue from each sacrificed animal were rinsed in washing buffer (Tris- $\mathrm{HCl} 0.1 \mathrm{M}, \mathrm{NaCl} 0.07 \mathrm{M}$, EDTA $0.005 \mathrm{M}$, $\mathrm{pH}$ 7.5) and homogenized in $1 \mathrm{ml}$ lysis buffer (Tris-HCL $10 \mathrm{mM} \mathrm{pH} \mathrm{7.5,} \mathrm{sucrose} 250 \mathrm{mM}, \mathrm{KCl}$ $100 \mathrm{mM}, \mathrm{MgCl}_{2} 5 \mathrm{mM}$, NaF $3.8 \mathrm{mM}$, NP-40 0.5\%, PMSF $0.1 \mathrm{mM}$ ) on ice. The homogenates were centrifuged at $16,000 \times \mathrm{g}$ at $4^{\circ} \mathrm{C}$ for $40 \mathrm{~min}$. Protein concentration was determined by the protein assay reagent method (Pierce Biotechnology, USA). The extracts (10 $\mu$ g protein) were mixed with SDS-PAGE sample buffer, boiled for $5 \mathrm{~min}$, separated by the electrophoresis on a $10 \%$ SDS polyacrylamide gel, and electroblotted onto ECL nitrocellulose membrane (R\&D Biotechnology, USA). The membranes were then blocked for 90 min with 5\% non-fat dry milk in Tris-buffered saline, incubated with monoclonal mouse anti-PCNA primary antibody and then with secondary antibody. The immunoblots were developed using an ECL detection kit.

Data are presented as means \pm SEM, unless otherwise stated. Statistical analyses were performed using the student's $t$ test $(\mathrm{P}<0.05)$.

\section{RESULTS}

No significant difference in mice BW was observed between the three groups at any stage of the experiment (data not shown). Neither was there any difference in the weights of the brain and liver between the groups at the time of killing. However, the relative lung weight [(lung weight / body weight $) \times 100 \%]$ of the control group [ $(1.36 \pm$ $0.18) \%$ ] was significantly higher than that of the DEYE-H $[(0.98 \pm 0.10) \%](\mathrm{P}=0.02)$ and DEYE$\mathrm{L}[(1.09 \pm 0.10) \%](\mathrm{P}=0.04)$ groups. The relative spleen weight $[$ (spleen weight / body weight) $\times 100 \%]$ of the control group $[(2.71 \pm 0.37) \%]$ was significantly lower than that of the DEYE-H [(3.43 $\pm 0.41) \%](\mathrm{P}=0.03)$ and DEYE-L $[(3.37 \pm 0.30)$ $\%](\mathrm{P}=0.04)$ groups.

Thirty-four days of oral administration of DEYE inhibited the growth of 4T1 cells transplanted in the mammary fat pad of female BALB/c mice. Primary tumour volumes were reduced to approximately $50 \%$ in the DEYE-H group and to $65 \%$ in the DEYE-L group of volumes of the control group (Fig 1).

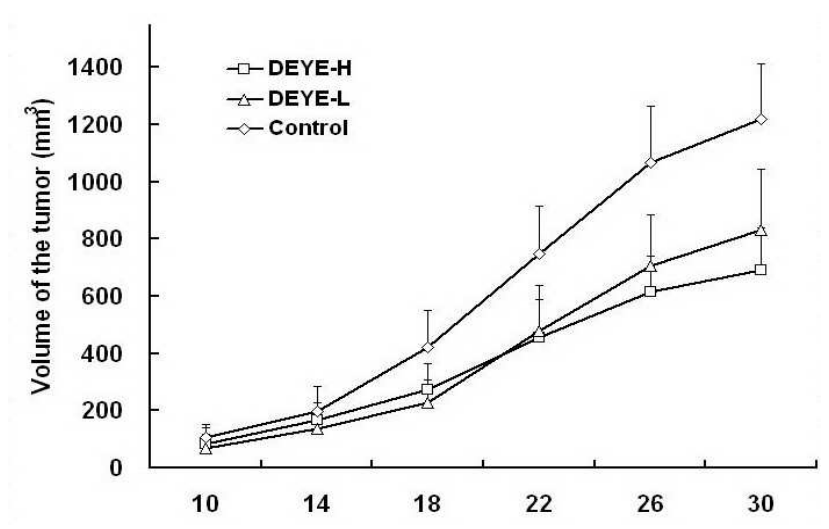

Figure 1 - DEYE inhibition of the growth of transplanted 4T1 mammary carcinoma. 4T1 cells were transplanted orthotopically in mammary fat pads of 4-week-old female BALB/c mice. DEYE was administered orally at a dose of $150 \mathrm{mg}$ or $50 \mathrm{mg} / \mathrm{kg}$ body weight from 4 days before cancer cell transplantation to the end of the treatment. Tumour volume (mean $\pm S D, n=6$ ) over time is reported. From day 18 on, tumour size in the DEYE-H group and DEYE-L group was significantly lower than in the control group $(\mathrm{P}<0.05)$. 
The DEYE treatment also reduced the metastasis of tumour in the lungs: the lungs of mice in the control group had 1.8 and 2.3 times more metastatic tumours compared to the DEYE-L ( $\mathrm{P}=$ $0.02)$ and DEYE-H $(\mathrm{P}=0.00)$ groups, respectively (Fig 2). Although the number of lung metastatic foci in the DEYE-L mice seemed less than that in the DEYE-H mice, there was no statistical difference between these two groups $(P=0.15)$. Mice administered DEYE-L and DEYE-H expressed lower amounts of PCNA compared to the control group (Fig 3).
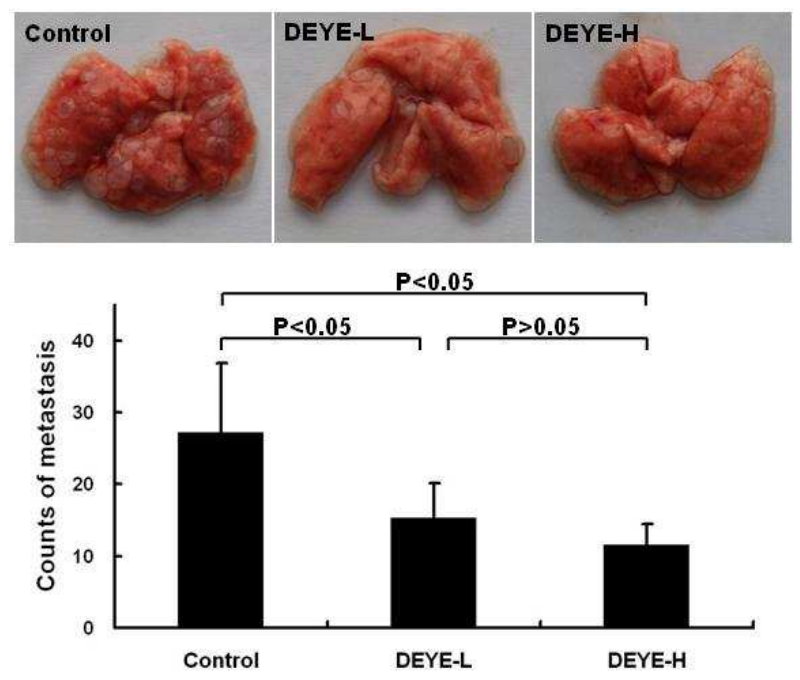

Figure 2 - DEYE inhibition of metastasis of 4T1 mammary carcinoma to the lungs. Mice receiving transplants of $4 \mathrm{~T} 1$ cells were administered with the extract orally. On day 34 of the treatment, the mice were asphyxiated, the lungs collected and the number of metastases in the five pulmonary lobes of each animal was expressed as the mean \pm $\mathrm{SD}(\mathrm{n}=6)$.

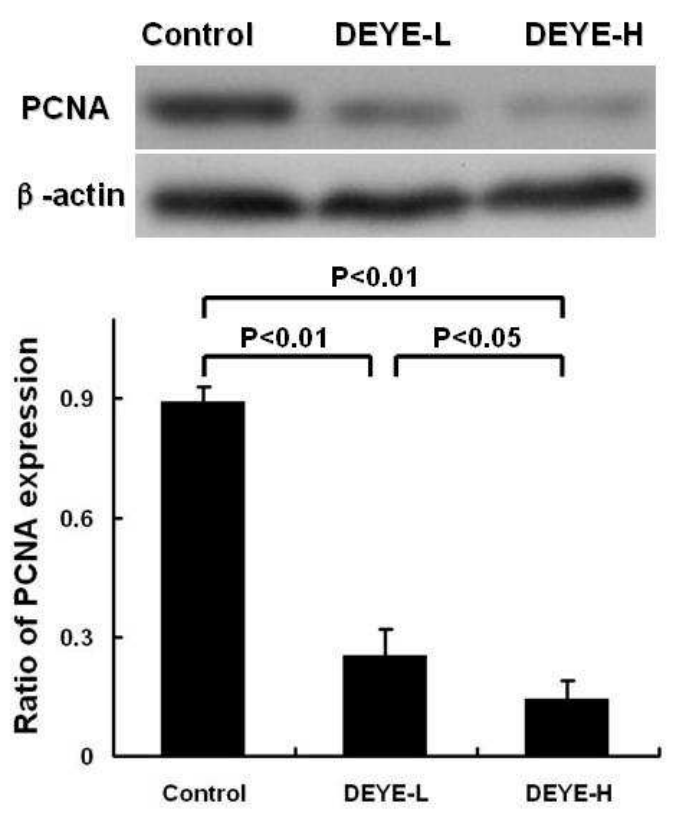

Figure 3 - PCNA protein expression in the lung tissues of DEYE treated mice and controls at day 30 following the injection of $4 \mathrm{~T} 1$ cells. Upper panel: Western blots detecting the PCNA protein and internal standard; lower panel: densities of PCNA bands as a percentage of $\beta$-actin standard. 


\section{DISCUSSION}

The present study supported the previous findings demonstrating that a fraction of red-yolked duck eggs (DEYE) enriched in carotenoids was able to inhibit the growth of mammary carcinoma in the animals. Furthermore, administration of the DEYE decreased the metastasis of implanted breast cancer cells in the lungs of the mice used in the study.

The inhibition of the growth of 4T1 carcinoma cells was dose-related. The administration of $50 \mathrm{mg} / \mathrm{kg}$ per day (mice group DEYE-L) slowed the growth by one third that of controls, while the administration of $150 \mathrm{mg} / \mathrm{kg}$ per day (mice group DEYE-H) slowed the growth by one half. A clear anti-metastases effect of DEYE was also observed and there was no statistical difference between the lung metastases numbers in the two mice groups receiving the extract. However, significantly less expression of PCNA protein was found in the lung tissues of high-dose DEYE treated mice. PCNA, an auxiliary protein of the DNA polymerase $\delta$, is a proliferation-associated marker used in different neoplasms in relation to clinical behavior and the expression of PCNA, which peaks in late $\mathrm{G} 1$ and $\mathrm{S}$ phases of the cell cycle, is positive in tumour cells (Huang et al., 2008). Thus, the present findings suggested that the DEYE administration not only decreased the metastasis of implanted carcinoma cells in the lungs but might inhibit the growth of metastasis tumour cells.

The results reinforced the probability that it was the carotenoid content of red-yolk duck eggs that was responsible its beneficial effects. In the past few decades, carotenoids have been used by the poultry industry for colouring the egg yolk and skin of chickens (Blanch and Hernández, 2000; Olson et al., 2008; Wall et al., 2010; Tanvez et al., 2009). For optimal egg yolk colouration, most studies have focused on the profile of carotenoids present in the egg yolk after feeding the ducks carotenoid-enriched diets (Hammershøj et al., 2010; Karadas et al., 2006). We have reported previously that ducks fed with the water plant $P$. crispus can produce red-yolk eggs of higher yolkcolour score with good taste and nutrition compared with other eggs (Wang et al., 2003). The pigments imparting the red colour were carotenoids originating from the $P$. crispus food source, which were mainly rhodoxanthin and its isomers (Liu et al., 2004a; Liu et al., 2006).
Carotenoids extracted from $P$. crispus have previously been shown to possess anti-oxidative and cancer-cell-depressive activities in vitro (Ren et al., 2005; Wang et al., 2005), and also antineoplastic and immunity enhancing effects in tumour-bearing animals (Ren et al., 2006b).

Carotenoids exhibit several biological activities that could prevent or slow the progression of cancer, including the inhibition of growth and malignant transformation and the promotion of apoptosis in transformed cells (Sumantran et al., 2000). Although initial interest in carotenoids focused primarily on their antioxidant activities, current evidence have suggested that the primary mechanisms by which carotenoids influenced the carcinogenesis was related to cell growth regulation, similar to the effects of retinoids (Bonanni and Lazzeroni. 2009). Carcinogenesis is a multistage process that results from several genetic and epigenetic events, involving the protooncogenes, tumour suppressor genes, and antimetastasis genes throughout the progression (Dong et al., 2009). The cancer continuum extends from the earliest cellular changes to a preneoplastic lesion, malignant tumour, and finally to metastasis. Carotenoids may influence various stages of the progression of cancer, but at which or by what mechanism remains to be ascertained.

The present study showed that oral administration of the extract of red yolk duck egg could lead to an inhibition of growth of orthotopic 4T1 tumour and reduce the metastasis of tumour in the lungs in mice. It might also be the case that, as a common food, natural red yolk duck egg might be a good alternative for the prevention or even cure of cancer for the humans.

\section{REFERENCES}

Blanch A and Hernández JM (2000) Red carotenoids for optimal yolk pigmentation. Feed Mix 8:9-12.

Bonanni B and Lazzeroni M (2009) Retinoids and breast cancer prevention. Recent Results Cancer Res 181:77-82.

Dey JH, Bianchi F, Voshol J, Bonenfant D, Oakeley EJ Hynes NE (2010) Targeting fibroblast growth factor receptors blocks PI3K/AKT signaling, induces apoptosis, and impairs mammary tumor outgrowth and metastasis. Cancer Res 70:4151- 4162.

Dong F, Budhu AS, Wang XW (2009) Translating the metastasis paradigm from scientific theory to clinical oncology. Clin Cancer Res 15:2588- 2593. 
Granados-Principal S, Quiles JL, Ramirez-Tortosa CL, Sanchez-Rovira P, Ramirez-Tortosa MC (2010) New advances in molecular mechanisms and the prevention of adriamycin toxicity by antioxidant nutrients. Food Chem Toxicol 48:1425-1438.

Hammershøj M, Kidmose U, Steenfeldt S (2010) Deposition of carotenoids in egg yolk by short-term supplement of coloured carrot (Daucus carota) varieties as forage material for egg-laying hens. $J$ Sci Food Agric 90:1163-1171.

Hasin BM, AJM Ferdaus, MA Islam, MJ Uddin, MS Islam (2006) Marigold and orange skin as egg yolk color promoting agents. Int J Poult Sci 5: 979-987.

Huang CS, Liao JW, Hu ML (2008) Lycopene inhibits experimental metastasis of human hepatoma SK-Hep1 cells in athymic nude mice. J Nutr 138: 538-543.

Jian YX, Li B, Wang JB, Chen JK (2003) Control of turion germination in Potamogeton crispus. Aquatic Botany 75: 59-69.

Karadas F, Grammenidis E, Surai PF, Acamovic T, Sparks NH (2006) Effects of carotenoids from lucerne, marigold and tomato on egg yolk pigmentation and carotenoid composition. $\mathrm{Br}$ Poult Sci 47: 561-566.

Liu LZ, Zhang M, Peng GH, Wang HB, Zhang SH (2004a) Separation and identification of red pigments in natural red yolk of duck's eggs by HPLC-MS-MS. Chin J Chrom 22:197-201.

Liu LZ, Zhang M, Huang J, Shi JY, Peng GH, Zhang SH (2004b) Effects of carotenoids extracts from natural red yolk on proliferation apoptosis of human liver cancer cell. Acta nutrimenta sinica 26: 457-459.

Liu LZ, Zhang M, Wang HB, Shi JY, Zhang SH (2003) Fringe study on carotenoids extraction of natural red yolk and its inhibition on S180 tumor. Food Sci 24:133-136.

Liu LZ, Zhang SH, Shi JY, Wei ZY (2006) Separation of the isomers of red carotenoid in nature red yolk with reverse-phase C18-HPLC. Food Sci 27:473-478.

Olson JB, Ward NE, Koutsos EA (2008) Lycopene incorporation into egg yolk and effects on laying hen immune function. Poult Sci 87:2573-2580.
Ren D, Peng G, Huang H, Wang H, Zhang S (2006a) Effect of rhodoxanthin from Potamogeton crispus L. on cell apoptosis in Hela cells. Toxicol In Vitro 20:1411-1418.

Ren DD, Huang HX, Peng GH, Wang HB, Zhang SH (2006b) Study on antitumor effect and immune function of carotenoids extract from Potamogeton crispus L. Food Sci 27:210-212.

Ren DD, Peng GH, Wang HB, Zhang SH (2005) Study on antioxidative effects of carotenoids extracted from Potamogeton crispus L. in vitro. Food Sci 26:228231.

Sumantran VN, Zhang R, Lee DS, Wicha MS (2000) Differential regulation of apoptosis in normal versus transformed mammary epithelium by lutein and retinoic acid. Cancer Epidemiol Biomarkers Prev 9:257-263.

Tanvez A, Amy M, Chastel O, Leboucher G (2009) Maternal effects and beta-carotene assimilation in Canary chicks. Physiol Behav 96:389-393.

Tapiero H, Townsend DM, Tew KD (2004) The role of carotenoids in the prevention of human pathologies. Biomed Pharmacother 58: 100-110.

Wall H, Jönsson L, Johansson L (2010) Effects on egg quality traits of genotype and diets with mussel meal or wheat-distillers dried grains with solubles. Poult Sci 89:745-751.

Wang HB, Peng GH, Liu LZ, Liu M, Ren DD, Shi JY, Zhang SH (2003) Studies on the carotenoids in Potamogeton crispus: comparisons on the characteristics of carotenoids between Potamogeton crispus and red-yolk duck eggs. Food Sci 24:41-45.

Wang HB, Zhang M, Huang J, Ren DD, Liu LZ, Shi JY, Li Z, Zhang SH (2005) Effect of carotenoids extracts from Potamogeton crispus on apoptosis of human hepatoma cell line QGY-7703 in vitro. Acta Biologiae Experimentalis Sinica 38:67-74.

Received: March 17, 2010; Revised: July 30, 2010; Accepted: March 16, 2011 